\title{
Agent-based Analysis and Simulation of Online Shopping Behavior in the Context of Online Promotion
}

\author{
Xiaoyi Deng \\ Business School, Huaqiao University, Quanzhou 362021, China \\ Corresponding Author Email: londonbell@hqu.edu.cn
}

https://doi.org/10.18280/rces.060104

Received: 8 February 2019

Accepted: 12 March 2019

\section{Keywords:}

agent-based analysis and simulation, online shopping behavior, consumer behavior, online promotion

\begin{abstract}
With the rapid development of E-commerce, a growing number of consumers have been attracted by online shopping. With the purpose of attracting more consumers, E-commerce sites usually apply various promotion strategies. Based on this, researches on consumer behaviors under online promotions gradually becomes a hot issue in the field of E-commerce. In the process of online shopping, the consuming decisions of consumers tend to be influenced by multiple factors, including consumers' experience of using online shopping website, the service reliability of online shopping and so on [1]. At present, the mathematical and statistical methods are most applied to construct consumer decision-making models in most researches. For the studies of consumers' online behaviors, the most popular methods are empirical research (such as sample-based analysis) [2], behavior-theory-based qualitative analysis and quantitative analysis methods based on data mining [3]. Regarding those methods, researches on consumer behaviors based on mathematical and statistical methods are based on static equilibrium.
\end{abstract}

\section{INTRODUCTION}

With the rapid development of E-commerce, a growing number of consumers have been attracted by online shopping. With the purpose of attracting more consumers, E-commerce sites usually apply various promotion strategies. Based on this, study of consumer behaviors in the condition of online promotion activities gradually becomes a hot issue in the field of E-commence. In the process of online shopping, the consuming decisions of consumers tend to be influenced by multiple factors, including consumers' experience of using online shopping website, the service reliability of online shopping and so on [1]. At present, the mathematical and statistical methods are most applied to construct consumer decision-making models in most researches. For the studies of consumers' online-behaviors, the most popular methods are empirical research (such as sample-based analysis) [2], behavior-theory-based qualitative analysis and quantitative analysis methods based on data mining [3]. Regarding those methods, researches on consumer behaviors based on mathematical and statistical methods are based on static equilibrium. Data mining and behavior-theory based analysis can reflect the characteristics of consumers' online consumption behaviors, but these methods cannot present the patterns of consuming behavior of consumers on the whole, under the influence of multiple internal and external factors. In addition, these methods strongly rely on existing transaction data [4], which are extremely difficult to collect. Therefore, an agent-based modeling and simulation (ABMS) method is put forward to analysis the patterns of online consumer behaviors in this paper. In our method, the heterogeneity of members in the system [5] can be reflected on the individual level of each consumers, by applying bottom-up modeling mode, and the shopping behaviors of consumers are simulated in consideration of various internal and external factors. And the effects of promotion strategies of shopping sites on consumers are analyzed and predicted through the emergent phenomenon of agent-based model.

Nowadays, ABMS methodology has been widely applied in many fields including power systems, emergency, traffic, transportation and so on [6-9]. In the related study area, Serrano et al. built an agent-based social simulation to analyze the use of social choice theory in ambient intelligence systems [10]; Zhang et al. [11] present a multi-agent simulation model of Chinese urban housing market. In recent years, agent-based simulation has been rapidly developed in the field of consumer behaviors. Schenk and Loffler [12] set up an agent-based model on consumers' behaviors in grocery shopping based on an individual population and store data gathered in northern Sweden; Cagil and Erdem [13] investigated online consumers' shopping behavior and built an agent-based model by using demographic characteristics based on empirical data gathered in Turkey. Roozmand et al. [14] put forward an agent-based model for the analysis of consumer decision-making based on culture, personality and human needs in eleven European countries. Kuhn et al. [15] summarized advantages of the ABMS in the field of consumer behaviors, and they pointed out that this methodology had a large development space in consumer behaviors area.

From the present researches, there are only a few studies combining consumer behaviors and online promotion strategies together. Therefore, in this paper, ABMS is utilized to analyze the influence of different promotion strategies on different consumers' purchasing decisions in different scenarios. Consumers' behaviors are analyzed and predicted by observing the emergent properties of the system. 


\section{RELATED WORKS}

\subsection{Problem statement}

During online shopping, the consumer decision-making process are influenced by internal factors and external factors. The internal factors refer to the personal characteristics of consumers, and the external ones refer to influences from sites and external environment. In general, the process of consumer decision-making can be divided into five stages: inspiring shopping desire, searching information, evaluating and choosing, making decision, and performing the purchasing behavior. Figure 1 indicates all factors that influences the online consumer behaviors, and the process of consumer decision-making. The individual characteristics like gender, age, annual income etc. are objective descriptions to evaluate the individual differences of consumers. Different consumer perceptions of online promotion will be generated due to the individual differences of consumers, which will divert their decision [16]. In this process, the internal factors' on consumers reflects their preference for external factors. In other words, the consumer preferences will be expressed via the effect of online promotion strategies, online promotion scenarios and product types. In addition, the consumer preferences to promotion strategies, promotion scenarios and product types are fuzzy [17].

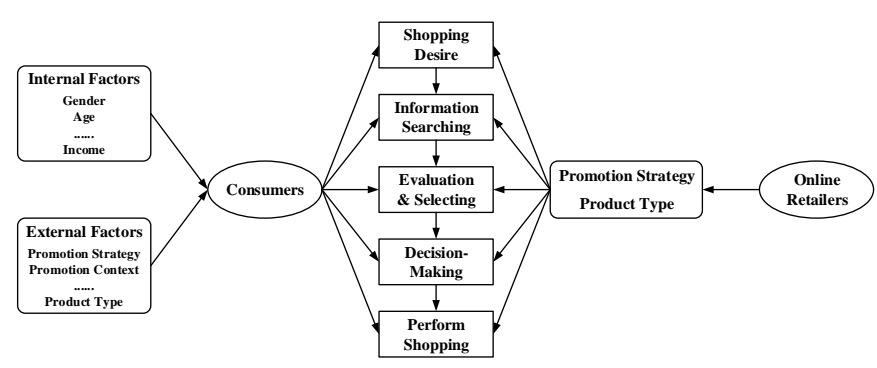

Figure 1. The process of consumer online decision-making and its influential factors

\subsection{Agent-based method}

Usually, questionnaire survey was mostly applied for empirical researches on consumer behaviors. The designed questionnaires will be sent out in advance to collect necessary information. After that, the collected data from questionnaires will be analyzed and summarized with statistical methods. The key issues of this study method lie in both the scientificity of questionnaire design and the configuration of sample size. In this paper, questionnaire survey and agent-based method are combined to analyze online consumer behaviors. There are two major advantages. On the one hand, it can effectively avoid the impact of the inadequacy of study samples. Because the ABMS method can generate multiple large sample data, each individual consumer in the system can be inflected to an agent, and its individual characteristics and behaviors can be referred to attributes and rules of agent respectively. The phenomenon of independence and interaction among consumers can be simulated via the interactive mechanism between agents. Based on this, the overall effects of consumers purchasing behavior (i.e. emergence) can be observed. Thus, the effect of promotion strategy can be evaluated. On the other hand, the consumers' decisions vary with individual characteristics and the sensitivity to changes of market environment. Therefore, in order to avoid the case neglecting individual influence in statistical methods and data mining methods, it is necessary to consider the influence of behavioral characteristics of individuals to the overall performance of the system.

\section{AGENT-BASED MODEL OF CONSUMER BEHAVIOR IN THE ONLINE PROMOTION CONTEXT}

\subsection{Research framework and hypotheses}

The research framework of this paper is shown in Figure 2, which includes, the analysis of the consumer online shopping behaviors, the extractions of individual attributes and external factors, the construction of consumer model, websites model and context model, the correlation analysis between different models, the configuration of the structures and functions of agents, the design of agents attributes and behavior rules, the operation of the model and data analysis, and also the observation of system emergence.

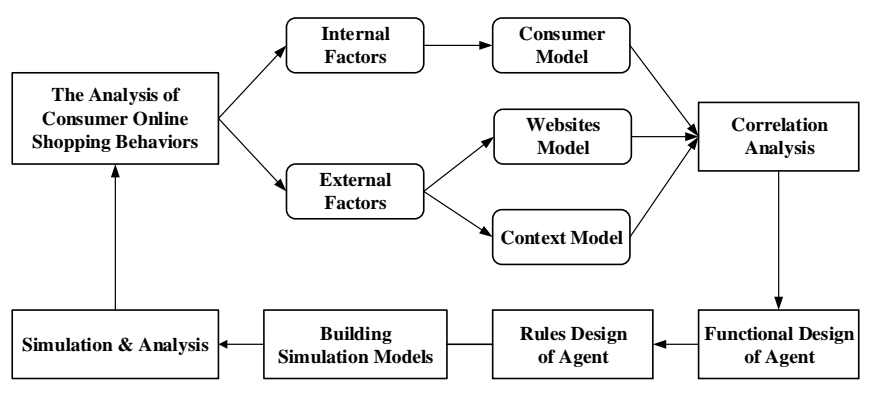

Figure 2. Research framework based on agent

The hypotheses in our model are stated as follows:

(1) Each consumer belongs to a certain consumer category.

(2) For the consumers of the same type, the fuzzy values of their performances are the same.

(3) The categories of available products online are limited.

(4) There is no such case like payment failure or commodity shortage.

Based on the stated above and surveys of previous studies [18], our questionnaire for online consumers is properly designed. The main purpose of questionnaire in this paper is to obtain the consumer profile and the consumer preference. The former one includes gender, age, vocation, income, etc. The latter one includes the consumer preferences to the online promotion strategies, promotion context, products types etc. In this study, 5000 questionnaires were sent out, and 4471 of them were available. The data collected through the questionnaires were utilized as the foundation of the agent model.

\subsection{Consumer model}

The consumer model consists of three parts: the consumer profile, the consumer preference and the shopping desire of consumer, which are defined as follows.

The consumer profile can be defined as a quintuple $C_{p}$, which is composed of five consumer characteristics sets, i.e. gender, age, education, vocation and monthly income, as shown in equation (1). 


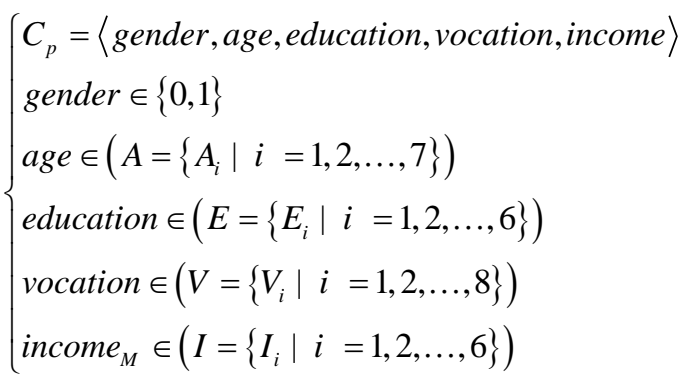

where, the gender set includes only two elements: male and female that are denoted by 1 and 0 , respectively. The age set is composed of 7 distinct sections: under 15, 16 25, 26 35, 36 40, 41 50, 51 60 and older than 60 . The education set contains 6 different education levels: under secondary academic degree, secondary academic degree, high school degree or equivalent, college degree, bachelor degree, and master degree or above. The vocation set consists of 8 different occupational categories, such as professionals, civil servants, management occupations, student and so on. The set of monthly income can be divided into 6 distinct sections: under 1500, 1500 3000, 3000 4500, 4501 6000, 6001 8000 and more than 8000 .

The consumer preference. The preference information is composited of the preference to promotion strategies, the preference to promotion contexts and the preference to product types, which is marked as a triple $P_{f}$, as shown in equation (2). These three different preferences are denoted by $P S, P C$ and $P T$, respectively.

$$
\left\{\begin{array}{l}
P_{f}=\langle P S, P C, P T\rangle \\
P S=\left\{P S_{1}, P S_{2}, \ldots, P S_{i}, \ldots, P S_{l}\right\}, P S_{i} \in[1,5], P S_{i} \in Z \\
P C=\left\{P C_{1}, P C_{2}, \ldots, P C_{i}, \ldots, P C_{m}\right\}, P C_{i} \in[1,5], P C_{i} \in Z \\
P T=\left\{P T_{1}, P T_{2}, \ldots, P T_{i}, \ldots, P T_{n}\right\}, P T_{i} \in[1,5], P T_{i} \in Z
\end{array}\right.
$$

where, three different preferences are denoted by $P S, P C$ and $P T$, respectively; the range of each consumer preference degree is from 1 to 5, which stand for "can't stand", "dislike", "don't mind", "like", "prefer", respectively. For instant, a consumer's preferences to promotion strategy, promotion context and product type are $P S_{1}=$ " like", $P C_{2}=$ "don't mind" and $P T_{3}=$ "dislikes" respectively, the preference value of this consumer is $<4,3,2>$; $l, m$ and $n$ stand for the types of promotion strategies, promotion contexts and promotion products, respectively

The shopping desire of consumers. It is used to describe the probability of the consumer perform online shopping behavior, and depend on individual consumptive habits. In this paper, the shopping desire of consumer is denoted by a real number $S D \in[0,1]$. If $S D=0$, it means that the consumer will not buy any product. However, if $S D=1$, it means that the consumer is about to buy a certain product.

Above all, the consumer model is defined in equation (3).

$$
C=\left\langle C_{P}, P_{f}\right\rangle=\langle\text { gender, age, education, vocation, income, } P S, P C, P T, S D\rangle
$$

\subsection{Websites model}

In this paper, websites model has two main functions. The former is to provide products, and the latter is to launch promotions.
The products generally fall into four categories according to the online shopping information of consumers. They are daily supplies $\left(P_{1}\right)$, digital products $\left(P_{2}\right)$, domestic appliance $\left(P_{3}\right)$, garments $\left(P_{4}\right)$, shoes and bags $\left(P_{5}\right)$, jewelry $\&$ accessories $\left(P_{6}\right)$, foods $\left(P_{7}\right)$, cosmetics $\left(P_{8}\right)$ and services $\left(P_{9}\right)$, as shown in equation (5).

$T_{p}=\left\{T_{1}, T_{2}, T_{3}, T_{4}, T_{5}, T_{6}, T_{7}, T_{8}\right\}$

The promotion strategies are denoted by set $S_{p}$, as shown in equation (4).

$S_{p}=\left\{S_{1}, S_{2}, S_{3}, S_{4}\right\}$

where, $S_{1}, S_{2}, S_{3}$ and $S_{4}$ stand for price discount, free shipping, gift coupon and seckilling, respectively.

\subsection{Context model}

Based on the statistical survey of the online promotion, five promotion context are summarized and described as follows:

(1) Festival and holiday $\left(C_{1}\right)$ : E-commerce websites can stimulate consumption by performing promotional activities in festivals and holidays.

(2) Anniversary $\left(C_{2}\right)$ : In order to attract consumers, online retailers will perform promotional activities on special day like anniversaries.

(3) Flash sale $\left(C_{3}\right)$ : online retailers will provide products with high discounts or very lower prices than usual in a very short period of time, which can help retailers to build brand loyalty.

(4) Off-season sales $\left(C_{4}\right)$ : Extend the selling time of products and attract consumers by reducing the price.

$(5)$ New products $\left(C_{5}\right)$ : When new products are online, they are lack of regular customers or word of mouth. Thus, online retailers usually employ new product promotion to attract consumers.

The set of promotion context are marked as $C_{t}$, as shown in equation (6)

$C_{t}=\left\{C_{1}, C_{2}, C_{3}, C_{4}, C_{5}\right\}$

Usually, the consumers' purchasing decision will be impacted by promotion contexts. Therefore, the effect of online promotion can be accurately reflected, when promotion contexts are taken into consideration.

\subsection{Rules design}

In this section, agents' rules are designed to predict purchasing behaviors of consumers, according to the consumer attributes in section 3.2. The main idea is to express the agents' behavior by means of "IF-THEN" and weighting function [19].

\subsubsection{Preference rules}

According to the value of consumer gender, age, education, vocation and income in equation (1), there are 4032 different types of consumers. The consumers of same type share the same preferences to promotion strategies $P S$, promotion contexts $P C$, and product types $P T$ referred to online retailers. 
First of all, relationship rules between the consumer profile and consumer preference are established, which can be stated as IF (Consumer Profile) THEN (Consumer Preference). Here, relationship rules between the consumer profile and promotion strategies are showed in Table 1. Due to space limitation, only a few rules are listed.

Table 1. The relationship rules of between the consumer profile and promotion strategies

\begin{tabular}{|c|c|c|c|c|c|c|c|c|c|c|}
\hline \multirow{3}{*}{$\begin{array}{c}\text { No. } \\
1\end{array}$} & \multicolumn{5}{|c|}{ Consumer Profile } & \multicolumn{5}{|c|}{ Consumer Preference } \\
\hline & \multirow{2}{*}{$\begin{array}{c}\text { gender } \\
\text { male }\end{array}$} & \multirow{2}{*}{$\frac{a g e}{A_{1}}$} & \multirow{2}{*}{$\frac{\text { education }}{E_{1}}$} & \multirow{2}{*}{$\frac{\text { vocation }}{V_{1}}$} & \multirow{2}{*}{$\begin{array}{c}\text { income } \\
I_{1}\end{array}$} & \multicolumn{5}{|c|}{ Promotion Strategies $(P S)$} \\
\hline & & & & & & 4 & 3 & 5 & $\ldots$ & 1 \\
\hline 2 & male & $A_{1}$ & $E_{1}$ & $V_{1}$ & $I_{2}$ & 4 & 3 & 5 & $\ldots$ & 2 \\
\hline 3 & male & $A_{1}$ & $E_{1}$ & $V_{1}$ & $I_{3}$ & 3 & 5 & 3 & $\ldots$ & 4 \\
\hline 4 & male & $A_{1}$ & $E_{1}$ & $V_{1}$ & $I_{4}$ & 3 & 5 & 3 & $\ldots$ & 4 \\
\hline 5 & male & $A_{1}$ & $E_{1}$ & $V_{1}$ & $I_{5}$ & 3 & 5 & 3 & $\ldots$ & 3 \\
\hline 6 & male & $A_{1}$ & $E_{1}$ & $V_{1}$ & $I_{6}$ & 3 & 5 & 3 & $\ldots$ & 3 \\
\hline 7 & male & $A_{1}$ & $E_{1}$ & $V_{2}$ & $I_{1}$ & 4 & 4 & 3 & $\ldots$ & 1 \\
\hline ... & $\cdots$ & $\ldots$ & $\ldots$ & $\cdots$ & $\ldots$ & $\cdots$ & $\ldots$ & $\ldots$ & $\cdots$ & $\cdots$ \\
\hline 4032 & female & $A_{7}$ & $E_{6}$ & $V_{8}$ & $I_{6}$ & 3 & 4 & 2 & $\ldots$ & 2 \\
\hline
\end{tabular}

In Table 1, rules can be divide into 2 parts: $\operatorname{IF}()$ and THEN(). The former part is used to describe the consumer attributes, and the latter part is applied to represent the consumer preferences. For example, assuming that in Rule $7, l=3$, this rule can be expressed as follows.

IF (gender $=$ male and age $=A_{1}$ and education $=E_{1}$ and vocation $=V_{2}$ and income $=I_{1}$ )
THEN $\left(P S_{1}=4, P S_{2}=4, P S_{3}=3\right)$

Similarly, relationship rules between the consumer profile and promotion contexts can be built, and the same between the consumer profile and product types can also be constructed, respectively, as shown in Table. 2 and Table. 3 .

Table 2. The relationship rules between the consumer profile and promotion contexts

\begin{tabular}{|c|c|c|c|c|c|c|c|c|c|c|}
\hline \multirow{3}{*}{$\begin{array}{l}\text { No. } \\
1\end{array}$} & \multicolumn{5}{|c|}{ Consumer Profile } & \multirow{2}{*}{\multicolumn{5}{|c|}{$\begin{array}{l}\text { Consumer Preference } \\
\text { Promotion Contexts }(P C)\end{array}$}} \\
\hline & gender & age & education & vocation & income & & & & & \\
\hline & male & $A_{1}$ & $E_{1}$ & $V_{1}$ & $I_{1}$ & 3 & 3 & 5 & $\ldots$ & 1 \\
\hline 2 & male & $A_{1}$ & $E_{1}$ & $V_{1}$ & $I_{2}$ & 3 & 3 & 5 & $\ldots$ & 1 \\
\hline 3 & male & $A_{1}$ & $E_{1}$ & $V_{1}$ & $I_{3}$ & 3 & 3 & 4 & $\ldots$ & 2 \\
\hline 4 & male & $A_{1}$ & $E_{1}$ & $V_{1}$ & $I_{4}$ & 3 & 4 & 3 & $\ldots$ & 2 \\
\hline 5 & male & $A_{1}$ & $E_{1}$ & $V_{1}$ & $I_{5}$ & 4 & 5 & 3 & $\ldots$ & 3 \\
\hline 6 & male & $A_{1}$ & $E_{1}$ & $V_{1}$ & $I_{6}$ & 4 & 5 & 3 & $\ldots$ & 3 \\
\hline 7 & male & $A_{1}$ & $E_{1}$ & $V_{2}$ & $I_{1}$ & 3 & 4 & 2 & $\ldots$ & 1 \\
\hline$\ldots$ & $\begin{array}{l}\ldots \\
\text { female }\end{array}$ & $\ldots$ & $\begin{array}{l}\cdots \\
E_{6}\end{array}$ & $\begin{array}{l}\ldots \\
V_{8}\end{array}$ & $\ldots$ & $\ddot{1}$ & 5 & 3 & $\begin{array}{l}\ldots \\
\ldots\end{array}$ & $\ddot{3}$ \\
\hline
\end{tabular}

Table 3. The relationship rules between the consumer profile and product types

\begin{tabular}{|c|c|c|c|c|c|c|c|c|c|c|}
\hline \multirow{3}{*}{$\begin{array}{c}\text { No. } \\
1\end{array}$} & \multicolumn{5}{|c|}{ Consumer Profile } & \multirow{2}{*}{\multicolumn{5}{|c|}{$\begin{array}{c}\text { Consumer Preference } \\
\text { Product Types }(P T) \\
\end{array}$}} \\
\hline & \multirow{2}{*}{$\frac{\text { gender }}{\text { male }}$} & \multirow{2}{*}{$\frac{a g e}{A_{1}}$} & \multirow{2}{*}{$\frac{\text { education }}{E_{1}}$} & \multirow{2}{*}{$\frac{\text { vocation }}{V_{1}}$} & \multirow{2}{*}{$\begin{array}{c}\text { income } \\
I_{1}\end{array}$} & & & & & \\
\hline & & & & & & 1 & 3 & 5 & $\cdots$ & 3 \\
\hline 2 & male & $A_{1}$ & $E_{1}$ & $V_{1}$ & $I_{2}$ & 1 & 3 & 5 & $\cdots$ & 3 \\
\hline 3 & male & $A_{1}$ & $E_{1}$ & $V_{1}$ & $I_{3}$ & 1 & 4 & 4 & $\ldots$ & 3 \\
\hline 4 & male & $A_{1}$ & $E_{1}$ & $V_{1}$ & $I_{4}$ & 1 & 4 & 4 & $\cdots$ & 4 \\
\hline 5 & male & $A_{1}$ & $E_{1}$ & $V_{1}$ & $I_{5}$ & 1 & 4 & 4 & $\ldots$ & 4 \\
\hline 6 & male & $A_{1}$ & $E_{1}$ & $V_{1}$ & $I_{6}$ & 1 & 5 & 3 & $\ldots$ & 5 \\
\hline 7 & male & $A_{1}$ & $E_{1}$ & $V_{2}$ & $I_{1}$ & 1 & 3 & 5 & $\ldots$ & 3 \\
\hline$\cdots$ & $\cdots$ & $\cdots$ & $\cdots$ & $\cdots$ & $\cdots$ & $\cdots$ & $\cdots$ & $\cdots$ & $\cdots$ & $\cdots$ \\
\hline 4032 & female & $A_{7}$ & $E_{6}$ & $V_{8}$ & $I_{6}$ & 2 & 4 & 2 & $\ldots$ & 5 \\
\hline
\end{tabular}

\subsubsection{Purchasing decision-making rules}

For all products available online, consumers' purchasing decisions at time $t$ are denoted by set $D^{t}, D^{t}=\left\{D_{i j}{ }^{t} \mid i=1,2, \ldots, M\right.$; $j=1,2, \ldots, N\}$, where $D_{i j}{ }^{t}=\{0,1\}$ and subscripts $i$ and $j$ stand for the ordinals of consumers and products respectively. If the $i$ th consumer buys the $p$-th product, $D_{i j}{ }^{t}=1$; otherwise, $D_{i j}{ }^{t}=0$.

Besides, purchasing decisions of consumers are impacted by promotion strategies $S_{p}$, promotion context $C_{t}$ and product types $T_{p}$. According to consumer model in section 3.2, the consumers' decision-making process is also affected by their shopping desire $S D$. Generally, the stronger the shopping desire of consumers is, the higher the possibility of purchasing products will be. So $S D$ is regarded as an influence coefficient of the consumer preference $P_{f}$. Thus, the consumer preference under the influence of shopping desire is defined as $P_{f}^{\prime}=S D \times P_{f}$, and the three different preferences $P S^{\prime}, P C^{\prime}$ and $P T^{\prime}$ are defined 
in equation (7).

$$
\left\{\begin{array}{l}
P_{f}{ }^{\prime}=\left\langle P S^{\prime}, P C^{\prime}, P T^{\prime}\right\rangle \\
P S^{\prime}=S D \cdot P S / 5 \\
P C^{\prime}=S D \cdot P C / 5 \\
P T^{\prime}=S D \cdot P T / 5
\end{array}\right.
$$

In equation (7), the values of $P S^{\prime}, P C^{\prime}$ and $P T$ are all in the interval $[0,1]$. The rule expression of consumers' purchasing decision is put forward as below.

$$
\begin{aligned}
& \text { IF }<\text { Condition } 1>\text { THEN }<\text { Decision } 1> \\
& \text { IF }<\text { Condition } 2>\text { THEN }<\text { Decision } 2> \\
& \text { IF }<\text { Condition } 3>\text { THEN }<\text { Decision } 3> \\
& \text { IF }<\text { Condition } 4>\text { THEN }<\text { Decision } 4> \\
& \text { IF }<\text { Condition } 5>\text { THEN }<\text { Decision } 5> \\
& \text { IF }<\text { Condition } 6>\text { THEN }<\text { Decision } 5> \\
& \cdots . . \\
& \text { IF }<\text { Condition } n>\text { THEN }<\text { Decision } n>
\end{aligned}
$$

The description of purchasing decision rules are stated as follows.

(1) In $P S^{\prime}, P C^{\prime}$ and $P T^{\prime}$, if anyone of them is larger than a certain threshold $\alpha$, it means that the consumer will purchase a particular item; otherwise, go to next step;

(2) In $P S, P C$ and $P T$, if the sum of any two of them is larger than a certain threshold $\beta$, the consumer will perform shopping behavior; otherwise, go to next step;

(3) Let $a, b, c$ be respectively the weights of $P S^{\prime}, P C^{\prime}$ and $P T$, which affect consumer decision-making. And $a, b$, $c \in(0,1)$. If the value of $a \cdot P S^{\prime}+b \cdot P C^{\prime}+c \cdot P T^{\prime}$ is larger than a certain threshold $\gamma$, the consumer will make a purchase. Otherwise, the consumer will do nothing and statements end.

In the simulation, the processes above will be performed on every consumer. Different results under different criteria can be produced by adjusting the values of parameters $a, b$ and $c$. The whole process is expressed in the form of "IF- THEN".

\section{EXPERIMENT AND RESULTS}

\subsection{Experimental Design}

In this research, our Agent-based simulation model is implemented with JAVA on the Repast. The Repast is an advanced, free and open source ABMS platform, which has many advantages, such as easy to learn, strong portability and scalability, etc. [20]. Microsoft SQL is employed to store consumers' information, including consumer profiles, consumer preferences and their correspondence, etc. The simulation procedure is composed of three main parts: model initialization, information acquisition and rule-based simulation.

\subsection{Experimental results}

In our model, 10000 consumers are generated and their online shopping behaviors are simulated. Meanwhile, four types of promotion strategies and five different contexts are set, so there are $4 * 5=20$ different combinations in total. From simulation results, consumers' changes in purchase probability before and after employing promotion strategies are shown in Table.4, where the column " $R A W$ " is the purchase probability without promotion.
Table 4. Consumers' purchase probability (\%) before and after promotions

\begin{tabular}{ccccccc}
\hline $\begin{array}{c}\text { Consumer } \\
\text { profile }\end{array}$ & Value & $S_{1}$ & $S_{2}$ & $S_{3}$ & $S_{4}$ & $R A W$ \\
\hline Gender & Male & 4.09 & 4.27 & 4.29 & 4.36 & 3.34 \\
& Female & 4.61 & 4.08 & 4.41 & 4.35 & 2.74 \\
Age & $A_{1}$ & 4.73 & 4.81 & 4.69 & 4.92 & 3.06 \\
& $A_{2}$ & 5.58 & 5.11 & 5.04 & 5.32 & 3.57 \\
& $A_{3}$ & 6.62 & 6.08 & 6.19 & 6.07 & 4.18 \\
& $A_{4}$ & 5.04 & 4.93 & 4.75 & 5.01 & 3.33 \\
& $A_{5}$ & 4.19 & 3.84 & 3.76 & 3.8 & 2.59 \\
& $A_{6}$ & 3.35 & 3.07 & 3.04 & 3.39 & 1.99 \\
Income & $A_{7}$ & 2.13 & 1.86 & 1.67 & 1.75 & 1.27 \\
& $I_{1}$ & 5.08 & 4.62 & 4.45 & 4.98 & 2.94 \\
& $I_{2}$ & 4.85 & 4.28 & 4.73 & 4.44 & 3.26 \\
& $I_{3}$ & 4.55 & 4.19 & 4.24 & 4.56 & 3.27 \\
& $I_{4}$ & 4.28 & 3.87 & 4.19 & 4.11 & 2.97 \\
& $I_{5}$ & 4.05 & 3.81 & 3.87 & 3.76 & 2.72 \\
& $I_{6}$ & 3.93 & 3.73 & 3.52 & 3.26 & 2.66 \\
\hline
\end{tabular}

From Table.4, it can be seen that purchase probabilities are improved by different promotion strategies, and the increasing rates are from $20.69 \%$ to $69.90 \%$.

(1) Consumer decision-making analysis based on personal characteristics

The effects of promotion strategies are denoted by set $W$ defined in equation (8), which is utilized to describe the consumers' decisions after employing different promotion strategies.

$W=\left(R^{\prime}-R\right) / R$

where, $R^{\prime}$ is the purchase probability of consumers after applying promotion strategies, $R$ stands for the purchase probability of consumers before applying promotion strategies.

According to the purchase probability data in Table 2, the specific impact of four promotion strategies are showed in Figures 3 to 6 .

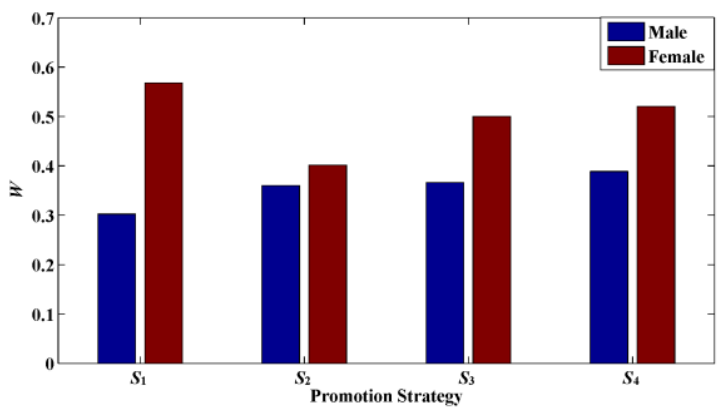

Figure 3. Effects of promotion strategies on consumers of different gender

In Figure 3, it represents the promotion strategies' effects on female and male consumers. The abssisa represents promotion strategies $S_{1}, S_{2}, S_{3}$ and $S_{4}$, corresponding to price discount, free shipping, coupons and seckilling, respectively. The ordinate stands for the effects of promotion strategies on consumers. From Figure 3, it is clear that consumers' gender leads to significant difference in promotion effects: the promotion strategies $s_{1}$ and $s_{2}$ have the largest impact and the smallest impact on females, respectively, and the promotion strategies $s_{4}$ and $s_{1}$ have the largest impact and the smallest impact on males, respectively. Generally, promotion strategies influence on females more obviously than males by $26.55 \%$, 
$4.15 \%, 13.38 \%$ and $13.19 \%$. The reason may be that females usually behave more emotionally rather than rationally in shopping. Thus, female consumers are more likely to be influenced by online promotion. This simulation results consist with facts.

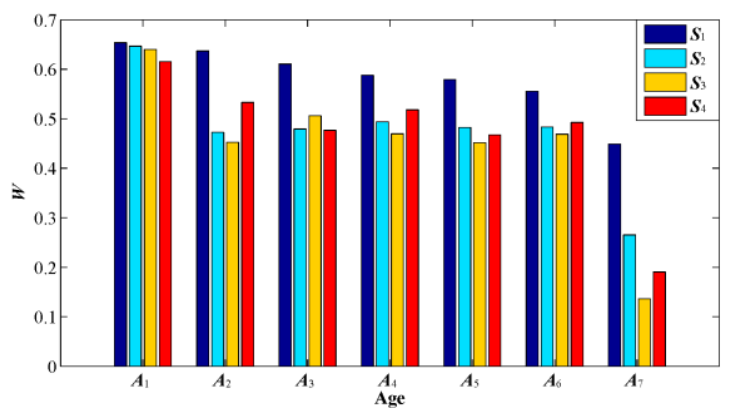

Figure 4. Effects of promotion stategies on consumers in different age groups

Figure 4 is referred to the degrees of different age counsumer influenced by the promotion strategy. The abscissa indicates the interval ranges of consumers' ages. As can be seen in Figure 4, the promotion strategy $S_{1}$ is more effective than the other three strategies. In contrast to the increasing of ages, the effect of promotion strategy is a trend of downward. Nevertheless, there are no obvious differences among the groups $A_{3}, A_{4}, A_{5}$ and $A_{6}$. But the influences of group $A_{7}$ have underperformed the previous six goups. Compared with $A_{1}$, there is a maximum difference, which reaches $50.38 \%$.

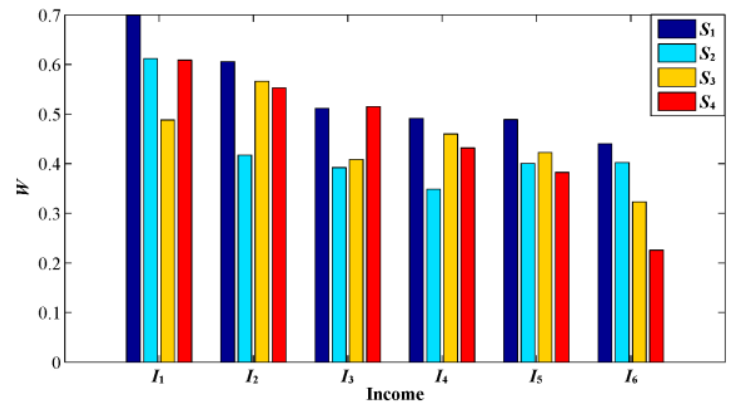

Figure 5. Effects of different promotion strategies on consumers with different income

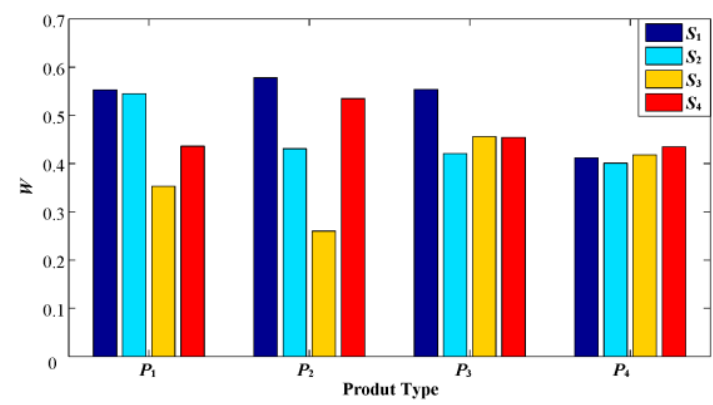

Figure 6. Effects of different promotion strategies on different product types

Figure 5 indicates the effect $W$ on consumers at different income level, where the abscissa shows the value range of consumers. From this figure, it is noted that promotion strategies strongly appeal to low-income consumers more, comparing with the high-income people. Comparing group $I_{1}$ with group $I_{6}$, four promotion strategies are more influencial to the former one than the later one by $25.91 \%, 20.98 \%$, $16.50 \%$ and $38.31 \%$, respectively. And the promotion strategy $S_{1}$ works better than the rest three ones, except for group $I_{2}$

In Figure 6, product types are analyzed, which corresponds with the abscissa. Regarding type $p_{1}$, it is not difficult to find the effects of promotion stratagies $s_{1}$ and $\mathrm{s}_{2}$ standing out from the rest two strategies. As for type $p_{2}$, stratagies $S_{1}$ and $S_{4}$ present the excellent sales promotion, compared with the other products types. And, $S_{1}$ performs the best selling result in type $p_{3}$. There is no significant difference for the four promotion strategies on $p_{4}$, of which the largest difference is $3.16 \%$. Overall, $S_{1}$ fits in all product types, the statistics are as follows: $54.18 \%, 56.23 \%, 53.49 \%, 39.42 \%$. But $s_{3}$ does not reach the ideal effect, it is only $25.33 \%$.

(2) Consumer decision-making analysis under different contexts

The promotion strategies' effects on consumers under different contexts are showed in Figure 7. The abscissa represents the promotion strategies applied by online retailers, where $R A W$ is referred to the unused promotion strategy. Five promotion contexts $C_{1}, C_{2}, C_{3}, C_{4}$ and $C_{5}$ respectively are Holidays and festivals, Anniversary, Flash sale, Off-seasonal sales and New products. From Figure 8, it is clear that consumers' purchasing probability is $C_{5}>C_{1}>C_{3}>C_{4}>C_{2}$, as in the decreasing order. Apprently, under context $C_{5}$, the influence of the promotion strategy is much higher than the other three. It is obvious to see even the same promotion strategy differs in effects under different contexts. And, the purchase probability of consumers is lower when the promotion strategy is not used.

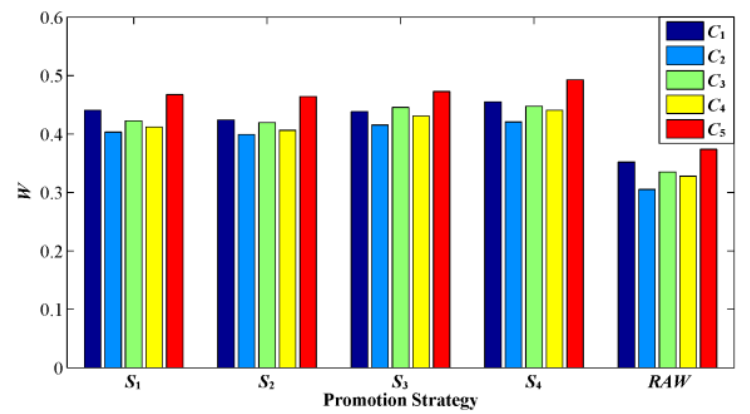

Figure 7. Effects of different promotion stratigies under different contexts

The contextual effects of on consumers with different characteristics are shown in Figure 8, Figure 9 and Figure 10.

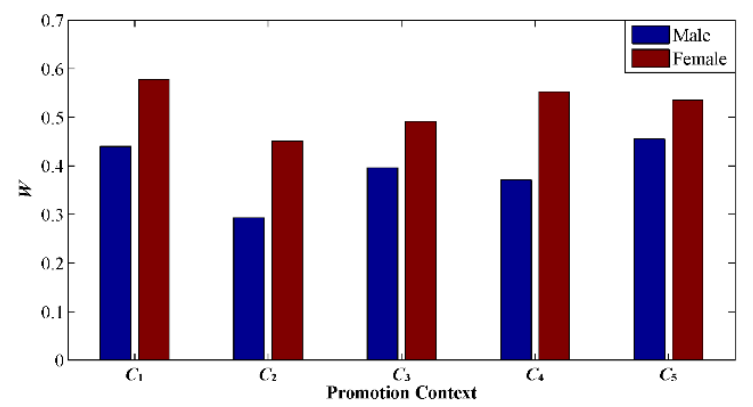

Figure 8. Effects of different promotion stratigies on female/male consumers under different contexts

In Figure 8, it shows that the female is more likely to be influenced by promotion context than the male. The effects on 
the female under four context are $13.60 \%, 15.80 \%, 9.60 \%$, $18.20 \%$ and $8.30 \%$ higher than that on the male, respectively. It is clear that the female is most influenced in the context of holidays and festivals, and the effects of new product promotion on males and females are almost the same.

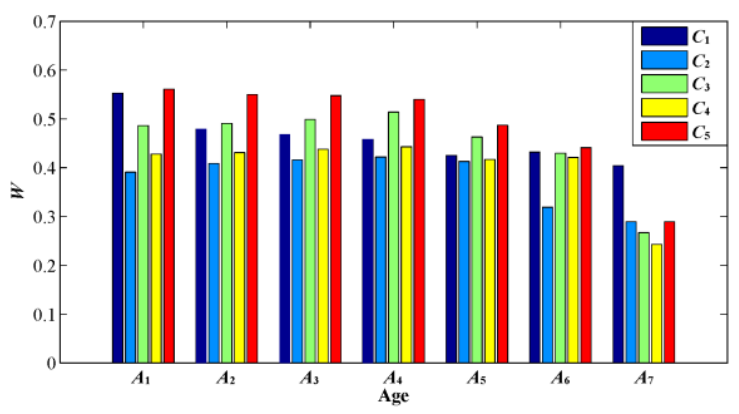

Figure 9. Effects of different promotion stratigies on consumers in different age under different contexts

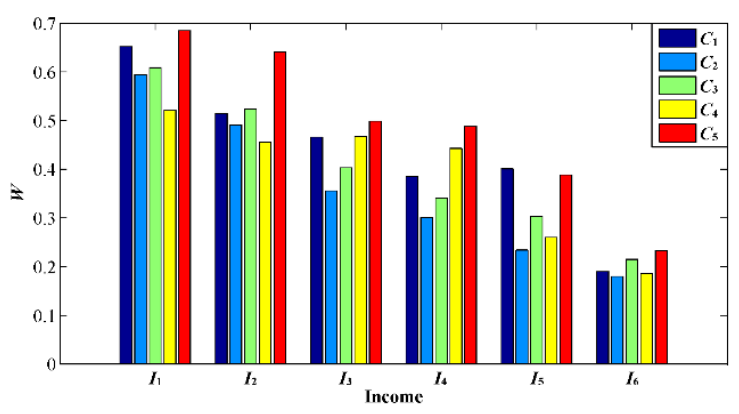

Figure 10. Effects of different promotion stratigies on consumers with different income under different contexts

Figure 9 depicts that young consumers are more likely to be influenced under all promotion contexts. Especially in the context of new product promotion, young consumers are $27.21 \%$ more influenced than senior consumers. In Figure 10, it shows that all promotion strategies under different contexts become less effective with growing income.

Compared with empirical researches, ABMS method can not only provide proof that different kinds of consumer characteristics, such as gender, age and income. These characteristics not only have different effects on online promotion [16], but also reveal more specific information about consumer behaviors with statistical and data analysis methods. Besides, consumers' online shopping behaviors can be predicted by emergent phenomenon of ABMS method. Thus, our method has strong practicability in analyzing consumers' online behaviors.

\section{CONCLUSION}

In this paper, ABMS method was applied to analyze the consumers' online shopping behavior under different promotion strategies. The conclusions are stated as follows:

(1) The purchase probability of consumers after the application of promotion strategies is significantly higher than that of the time when promotion strategies are not applied.

(2) In general, promotion strategies appeal to females more than to males; young consumers are more likely to be influenced by promotion strategies than senior consumers; promotion strategies has more impact on lower-income consumers than higher-income consumers; Price discounts have better promotion effect for all types of products.

(3) Consumers' purchase intension will be influenced under specific promotion contexts. Thus, the promotion strategies can play a better role under a proper context.

Therefore, targeted promotion strategies should be applied in marketing process, according to different types of consumers. In addition, in order suitable promotion strategies should be adopted to attract more consumers, by taking advantage of information of actual transactional context.

The strength of ABMS to analyze consumer online behaviors are listed as below: Firstly, diverse data can be generated from simulation model. Thus, the limitation of sample coverage in empirical research, and the difficulty for data collecting with data mining method can be both avoided effectively. Secondly, the overall impact of online promotion strategies on consumers' online shopping behaviour can be shown, according to agents' autonomous behaviors under the influence of all kinds of factors. Therefore, this research can provide a new way for consumer behavior analysis. Our future research will focus on improving the rationality of parameters selection and analysis precision in simulation.

\section{ACKNOWLEDGMENTS}

We gratefully acknowledge the support from the National Natural Science Foundation of China under granted No. 71401058 and No. 61300139.

\section{REFERENCE}

[1] Kim J, Fiore AM, Lee HH. (2007). Influences of online store perception, shopping enjoyment, and shopping involvement on consumer patronage behavior towards an online retailer. Journal of Retailing and Consumer Services 14(2): 95-107. https://doi.org/10.1016/j.jretconser.2006.05.001

[2] Chang YP, Zhu DH. (2007). Factors influencing consumers' intention of online-shopping: An empirical study from the angle of consumer innovativeness. Chinese Journal of Management 4(6): 820-823.

[3] Zhang T, Zhang D. (2007). Agent-based simulation of consumer purchase decision-making and the decoy effect. Journal of Business Research 60(8): 912-922. https://doi.org/10.1016/j.jbusres.2007.02.006

[4] Changchien SW, Lee CF, Hsu YJ. (2004). On-line personalized sales promotion in electronic commerce. Expert Systems with Applications 27(1): 35-52. https://doi.org/10.1016/j.eswa.2003.12.017

[5] Schramm ME, Trainor KJ, Shanker M, Hu MY. (2010). An agent-based diffusion model with consumer and brand agents. Decision Support Systems 50(1): 234-242. https://doi.org/10.1016/j.dss.2010.08.004

[6] Kilkki O, Kangasrääsiö A, Nikkilä R, Alahäivälä A, Seilonen I. (2014). Agent-based modeling and simulation of a smart grid: A case study of communication effects on frequency control. Engineering Applications of Artificial Intelligence 33: 91-98. https://doi.org/10.1016/j.engappai.2014.04.007

[7] Tan L, Hu M, Lin H. (2015). Agent-based simulation of building evacuation: Combining human behavior with predictable spatial accessibility in a fire emergency. 
Information Sciences 295: 53-66. https://doi.org/10.1016/j.ins.2014.09.029

[8] Yu Y, Kamel AE, Gong G, Li F. (2014). Multi-agentbased modeling and simulation of microscopic traffic in virtual reality system. Simulation Modelling Practice and Theory 45:

62-79. https://doi.org/10.1016/j.simpat.2014.04.001

[9] Holmgren J, Davidsson P, Persson JA, Ramstedt L. (2012). TAPAS: A multi-agent-based model for simulation of transport chains. Simulation Modelling Practice and Theory 23: 1-18. https://doi.org/10.1016/j.simpat.2011.12.011

[10] Serrano E, Moncada P, Garijo M, Iglesias CA. (2014). Evaluating social choice techniques into intelligent environments by agent based social simulation. Information $\quad$ Sciences 286: 102-124. https://doi.org/10.1016/j.ins.2014.07.021

[11] Zhang H, Li Y, Li H. (2013). Multi-agent simulation of the dynamic evolutionary process in Chinese urban housing market based on the GIS: The case of Beijing. Automation in Construction 35: 190-198. https://doi.org/10.1016/j.autcon.2013.05.010

[12] Schenk TA, Loffler G, Rauh J. (2007). Agent-based simulation of consumer behavior in grocery shopping on a regional level. Journal of Business Research 60(8): 894-903. https://doi.org/10.1016/j.jbusres.2007.02.005

[13] Cagil G, Erdem MB. (2012). An intelligent simulation model of online consumer behavior. Journal of Intelligent Manufacturing 23(4): 1015-1022. https://doi.org/10.1007/s10845-010-0439-7

[14] Roozmand O, Ghasem-Aghaee N, Hofstede GJ, Nematbakhsh MA, Baraani A, Verwaart T. (2011). Agent-based modeling of consumer decision making process based on power distance and personality. Knowledge-Based Systems 24(7): 1075-1095. https://doi.org/10.1016/j.knosys.2011.05.001

[15] Kuhn JR, Courtney JF, Morris B, Tatara ER. (2010). Agent-based analysis and simulation of the consumer airline market share for Frontier Airlines. Knowledge$\begin{array}{lll}\text { Based } & \text { Systems } & \text { 23(8): }\end{array}$ https://doi.org/10.1016/j.knosys.2010.06.002

[16] Ailawadi KL, Gedenk K, Langer T, Ma Y, Neslin SA. (2014). Consumer response to uncertain promotions: An empirical analysis of conditional rebates. International Journal of Research in Marketing 31(1): 94-106. https://doi.org/10.1016/j.ijresmar.2013.08.002

[17] Chan KY, Kwong CK, Law MC. (2014). A fuzzy ordinary regression method for modeling customer preference in tea maker design. Neurocomputing 142: 147-154. https://doi.org/10.1016/j.neucom.2013.12.056

[18] Palazon M, Delgado-Ballester E. (2011). The expected benefit as determinant of deal-prone consumers' response to sales promotions. Journal of Retailing and Consumer Services, 18(6): $542-547$. https://doi.org/10.1016/j.jretconser.2011.07.004

[19] Sonderegger-Wakolbinger LM, Stummer C. (2015). An agent-based simulation of customer multi-channel choice behavior. Central European Journal of Operations Research 23(2): 459-477. https://doi.org/10.1007/s10100-015-0388-5

[20] Wu J, Hu B, Zhang J, Fang D. (2008). Multi-agent simulation of group behavior in E-Government policy decision. Simulation Modelling Practice and Theory 16(10): https://doi.org/10.1016/j.simpat.2007.07.007 